\title{
Review Article \\ Role of STAT3 in Cancer Metastasis and Translational Advances
}

\author{
Mohammad Zahid Kamran, Prachi Patil, and Rajiv P. Gude \\ Gude lab, Advanced Centre for Treatment, Research \& Education in Cancer (ACTREC), Tata Memorial Centre, Kharghar, \\ Navi Mumbai 410210, India \\ Correspondence should be addressed to Rajiv P. Gude; rgude@actrec.gov.in
}

Received 29 April 2013; Revised 25 August 2013; Accepted 26 August 2013

Academic Editor: Jeroen T. Buijs

Copyright (C) 2013 Mohammad Zahid Kamran et al. This is an open access article distributed under the Creative Commons Attribution License, which permits unrestricted use, distribution, and reproduction in any medium, provided the original work is properly cited.

\begin{abstract}
Signal transducer and activator of transcription 3 (STAT3) is a latent cytoplasmic transcription factor, originally discovered as a transducer of signal from cell surface receptors to the nucleus. It is activated by tyrosine phosphorylation at position 705 leading to its dimerization, nuclear translocation, DNA binding, and activation of gene transcription. Under normal physiological conditions, STAT3 activation is tightly regulated. However, compelling evidence suggests that STAT3 is constitutively activated in many cancers and plays a pivotal role in tumor growth and metastasis. It regulates cellular proliferation, invasion, migration, and angiogenesis that are critical for cancer metastasis. In this paper, we first describe the mechanism of STAT3 regulation followed by how STAT3 is involved in cancer metastasis, then we summarize the various small molecule inhibitors that inhibit STAT3 signaling.
\end{abstract}

\section{Introduction}

STAT family proteins are latent cytoplasmic transcription factors initially discovered as acute phase response factors in 1994 [1]. These belong to a highly conserved family of protein, and comprise seven members, STAT1 to STAT4, STAT5a, STAT5b, and STAT6 $[2,3]$. In resting cells, STATs are generally located in the cytoplasm in their inactive state. Phosphorylation of specific tyrosine residue is an essential step for STAT activation. Once activated, STAT dimerizes to other STATs by reciprocal SH2 phosphotyrosine interaction, leading to its translocation into the nucleus followed by its binding to the specific enhancer elements for initiation of transcription [2, 3] (Figure 1). Studies from knockout mice revealed that individual STAT protein is essential for various normal physiological functions such as embryonic development, cell differentiation, immune response, and organogenesis [4] (Table 1).

All seven human STAT proteins range between 750 and 850 amino acids and are located on three chromosomal clusters $[3,5,6]$. The genes encoding STAT1 and STAT4 are located on chromosome 2, STAT2 and STAT6 on chromosome 17, and STAT3, STAT5a, and STAT5b on chromosome 12. Structural studies revealed that all STAT family proteins have seven structurally and functionally conserved domains including the amino-terminal domain (NH2), coiled-coil domain, DNA-binding domain (DBD), linker domain (Lk), SH2 domain, tyrosine activation domain $(\mathrm{Y})$, and transactivation domain (TAD) that have distinct roles [3]. The amino-terminal domain spans up to 125 amino acid residues and is involved in the formation of homotypic dimers among unphosphorylated STATs in resting cells. The coiled-coil domain interacts with various regulatory proteins and other transcription factors. The DNA-binding domain is involved in the direct binding of STATs to the corresponding sites in gene promoter. The linker domain adjacent to DNA binding maintains an appropriate conformation between the dimerization domain and DNA-binding domain. Next, the $\mathrm{SH} 2$ domain, which is a highly conserved domain, is involved in formation of active STAT dimer. The tyrosine activation domain consists of a conserved tyrosine residue usually nearby position 700. Phosphorylation of this tyrosine residue is essential for STAT activation. Finally, the carboxyl-terminal transactivation domain, a highly variable domain in context of length and sequence among STAT family members, regulates transcriptional activation of target genes through interaction with other transcriptional regulators. Conserved serine phosphorylation site is present in many transactivation domains. Phosphorylation of this serine residue is required for maximal transcriptional activity $[7,8]$. 
TABLE 1: Phenotype of STATs knockout mice.

\begin{tabular}{|c|c|}
\hline $\begin{array}{l}\text { Targeted } \\
\text { gene }\end{array}$ & Phenotype \\
\hline STAT1 & $\begin{array}{l}\text { Compromised innate response to microbial pathogens } \\
\text { and viruses. }\end{array}$ \\
\hline STAT2 & $\begin{array}{l}\text { Increased susceptibility to viral infection and a loss } \\
\text { of biological response to type I IFN. }\end{array}$ \\
\hline STAT3 & Early embryonic lethality. \\
\hline STAT4 & $\begin{array}{l}\text { Impaired natural killer cell cytotoxicity and Thl cell } \\
\text { response. }\end{array}$ \\
\hline $\begin{array}{l}\text { STAT5a } \\
\text { and } 5 b\end{array}$ & No mammary gland development or lactogenesis. \\
\hline STAT6 & No Th2 cells development. \\
\hline
\end{tabular}

Among seven mammalian STAT proteins, persistent activation of STAT3 followed by STAT5 is frequently detected in majority of human cancer cell lines and tumor tissues $[9,10]$. These include breast cancer, lung cancer, pancreatic cancer, head and neck cancer, prostate cancer, ovarian cancer, melanoma, leukaemias, and lymphomas. It is observed that aberrant STAT3 activation in tumor cells is associated with cell proliferation, cell survival, invasion, angiogenesis, and metastasis [11] (Figure 1). Conversely, targeting STAT3 activation inhibits tumor growth and metastasis both in vitro and in vivo without affecting normal cells, thus suggesting that STAT3 could be a valid molecular target for cancer therapy [12].

\section{Mechanisms of STAT3 Activation}

STAT3 is activated by phosphorylation of a single tyrosine residue located at position 705 . Various tyrosine kinases that catalyze this phosphorylation include such receptors with intrinsic tyrosine kinase activity as epidermal growth factor (EGFR), vascular endothelial growth factor receptor (VEGFR), platelet derived growth factor receptor (PDGFR), and colony stimulating factor- $1[13,14]$. Along with the nonreceptor tyrosine kinases such as Src and abl, cytokine receptors such as IL6R that show association with JAKs also catalyse the tyrosine phosphorylation $[1,15,16]$. Apart from tyrosine kinases, various serine kinases such as MAPK (p38MAPK, ERK, JNK), PKC ${ }^{\delta}$, mTOR, and NLK have been reported to phosphorylate STAT3 at serine position 727 which is required for STAT3 maximal transcriptional activity $[8,17-20]$. Additionally, STAT3 is also acetylated on a single lysine residue located at position 685 by histone acetyl transferase p300 [21]. This acetylation appears to regulate both transcriptional activity and homodimer stability [21]. Other factors such as UV radiation or sun light, carcinogen, stress, smoke, and infection are also known to play a significant role in STAT3 activation.

\section{Regulation of STAT3 Activity}

STAT3 activation is negatively regulated through numerous mechanisms which involves the following.
3.1. Tyrosine Phosphatases. Since tyrosine kinases play an important role in STAT3 activation, it is not surprising that tyrosine phosphatases are likely to play a role in STAT3 deactivation. These include classical protein tyrosine phosphatases (PTPs), dual-specificity phosphatases, and low molecular weight phosphatases [22]. Although these protein tyrosine phosphatases show little sequence similarity, these proteins exhibit similar tertiary structure and are characterized by presence of signature motif VHCSXGXGR[T/S]G $[23,24]$. The classical PTPs are divided into 2 groups, the transmembrane tyrosine phosphatase CD45 and nontransmembrane PTPs, including SH2-domain-containing SHP1 and SHP2, phospho-tyrosine phosphatase $1 \mathrm{~B}$ (PTP1B), and $\mathrm{T}$ cell-protein tyrosine phosphatase (TC-PTP). Increased JAK2 and STAT3 phosphorylation in response to targeted disruption of the CD45 gene was reported by Irie-Sasaki and coworkers [25]. Also, loss of SHP1 enhances JAK3 and STAT3 phosphorylation [26] while hepatocytedeletion of SHP2 promotes STAT3 signaling [27].

Apart from PTPs, dual-specificity phosphatases dephosphorylate both phosphotyrosine and phosphoserine/phosphothreonine. STAT3 is phosphorylated in response to angiotensin II at tyrosine and serine residues in vascular smooth muscle cells [28]. PP2B, a dual-specificity phosphatase, dephosphorylates STAT3 tyrosine phosphorylation, while protein phosphatase 2A (PP2A) dephosphorylates STAT3 serine phosphorylation [28].

Higher expression of low molecular weight phosphatase is generally observed in megakaryoblastic cells. In DAM1 megakaryocytic cells, low molecular weight phosphatase dephosphorylates STAT5 by interacting with its C-terminal domain [29].

3.2. Protein Inhibitors of Activated STATs (PIAS). The PIAS family proteins consisting of five members, namely, PIAS1, PIAS3, PIASy, PIASxa, and PIASxb, have been proposed to regulate the activity of many transcription factors, including STATs [30-35]. Amino-terminal region of all PIAS proteins is characterized by conserved LXXLL signature motif [31]. Other conserved elements of PIAS proteins include zinc binding domain, acidic domain, and serine/threonine rich regions; however, PIASy lacks serine/threonine rich domain [31]. PIAS mediated gene regulation involves direct blocking of DNA-binding activity of transcription factors, recruiting transcriptional corepressors or coactivators, and promoting protein sumoylation [30]. It has been proposed that PIAS1, PIAS3 and PIASx interact with STAT1, STAT3, and STAT4 respectively [32, 33, 35]. PIASy also interacts with STAT1 [34]. PIAS1 and PIAS3 repress transcriptional activity of STAT1 and STAT3, respectively $[32,33]$, whereas PIASx and PIASy repress the transcriptional activity of STAT1 and STAT4 [34, 35].

3.3. Suppressors of Cytokine Signaling (SOCS) Proteins. SOCS family proteins are inducible, with $\mathrm{SH} 2$ domain containing inhibitors of cytokine signaling, and consist of eight members: CIS along with SOCS1 to SOCS7 [36-38]. These inhibit STATs signaling in three ways, either by binding their $\mathrm{SH} 2$ 


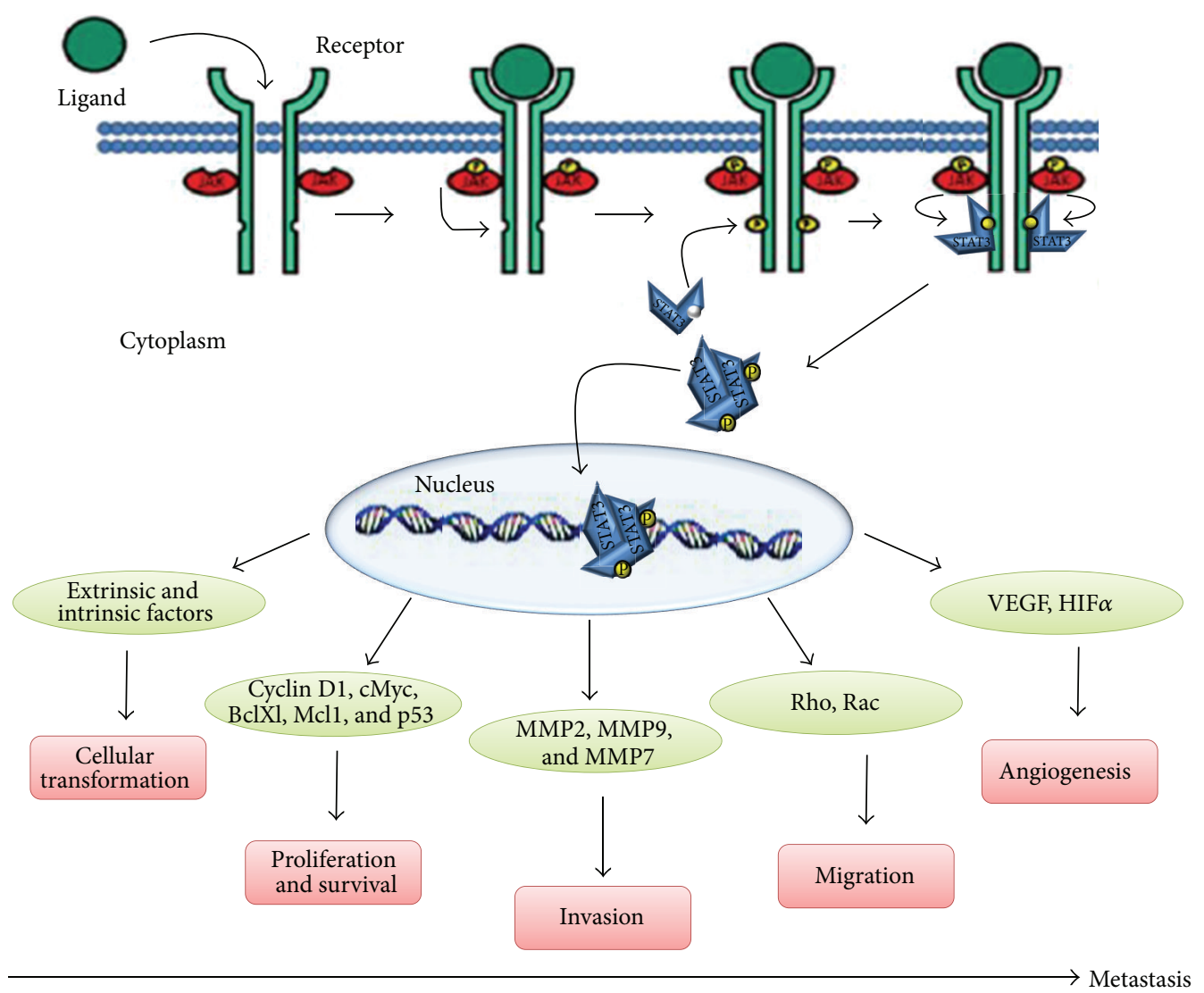

FIGURE 1: Binding of various ligands to their cognate cell surface receptors, results in phosphorylation of STAT3 molecules that further dimerizes with each other at SH2 domain and gets translocated to the nucleus. Following translocation, the dimerized STAT3 molecule binds to the promoter of target genes and activates their transcription. STAT3 regulate Cyclin D1, cMyc, BclXL, Mcl1 and p53, thereby regulating cellular proliferation and survival. STAT3 directly binds to the promoter of MMP2 and upregulates its expression. Additionally, STAT3 also regulate activity of MMP9 and MMP7. STAT3 regulates cellular migration by modulating the activity of Rho and Rac. Angiogenesis required for tumor growth and metastasis. STAT3 is seen to be regulating angiogenesis by upregulating the activity of VEGF and HIF $\alpha$.

domain to JAKs (in case of SOCS1), by binding to receptor cytoplasmic domain (in case of SOCS3), or by competing with STAT-SH2 domains for the recruitment to the receptor complex (CIS, SOCS2) [39]. In addition, SOCS proteins also induce proteasomal degradation pathway through SOCS box [40].

\section{Role of STAT3 in Cancer Metastasis}

Cancer metastasis is a complex, multistep process in which tumor cells primarily invades surrounding tissue and basement membrane, thus entering into blood circulation; while surviving during circulation, the tumor cells extravasate and adhere into distant organ and induce angiogenesis to form secondary tumor. Compelling evidence supports the fact that STAT3 activation plays a critical role in every step of metastasis including cell proliferation and survival, invasion, migration, and angiogenesis (Figure 1). The detailed explanation of how STAT3 regulates different steps of metastasis is described below.
4.1. STAT3 and Cell Transformation. Malignant transformation of cells by various protein tyrosine kinases, oncogenes, and viruses is mediated through STAT3 activation. Bromberg and coworkers for the first time reported that STAT3 could itself be responsible for cellular transformation [41]. By using NIH3T3 cell, Turkson and coworkers showed that STAT3 activation by Src may contribute to cell transformation by preventing apoptosis, thereby indirectly increasing cell numbers [42]. Yu and coworkers demonstrated that STAT3 is activated in interleukin- 6 induced transformation in mouse skin epithelial cells. [43]. Miranda and coworkers unveiled the role of STAT3 in in vitro transformation that was triggered by TRK oncogene [44]. Similarly, the transformation of NIH3T3 fibroblast by RET/PTC tyrosine kinase was mediated through the activation of STAT3 [45]. Hepatitis C virus core protein, large tumor antigen of simian virus 40 , and herpesvirus Saimiri STP-A oncoprotein have all shown their respective roles in transforming the cells through activation of STAT3 [46-48]. In contrast, targeting STAT3 decreases malignant transformation susceptibility of a number of cell 
types [49]. Thus, these observations strengthen the role of STAT3 in malignant transformation.

4.2. STAT3 and Cellular Proliferation and Apoptosis. In addition to being involved in cellular transformation, STAT3 also participates in cellular proliferation and survival. Both $\mathrm{cMyc}$ and cyclin D1 are required for regulation of G1 phase of cell cycle [50]. Evidence indicates that constitutive STAT3 signalling is associated with upregulation of cyclin D1 and cMyc expression, contributing to accelerated cell-cycle progression. STAT3 has also been shown to upregulate the expression of growth promoting gene pim-1 [51]. Consistent with its role in cellular proliferation, various studies have demonstrated that STAT3 signaling provides survival signals and suppresses the apoptosis in cancerous cells. These effects are mediated through the expression of $\mathrm{Bcl} 2, \mathrm{BclxL}, \mathrm{Mcl}$, surviving, and cIAP2 [52]. In addition, STAT3 negatively regulates the expression of $\mathrm{p} 53$, which is considered to be the most common inhibitor of cellular proliferation as well as inducer of apoptosis [53]. However, recent studies suggest that STAT3 can also act as a proapoptotic factor, especially during postlactation regression where LIF acts as the only activator of STAT3 to cause apoptosis in mammary glands [54]. In addition to pro-apoptotic function of STAT3, some studies suggested that loss of STAT3 promotes cellular proliferation and transformation [55].

4.3. STAT3 and Cellular Invasion. Invasion to extracellular matrix is one of the key steps in tumor growth and metastasis formation. Several lines of evidence strongly implicate that STAT3 plays a crucial role in this complex multistep process by regulating the matrix metalloproteinases (MMPs). In cutaneous squamous cell carcinoma, overexpression of phosphorylated STAT3 correlated with increased invasion, and metastasis [56]. In contrast, targeting STAT3 blocks tumor growth, invasion and metastasis formation in variety of cell lines both in vitro and in vivo [57]. Furthermore, STAT3 knockdown using ShRNA reduced pancreatic cancer cell invasiveness and MMP-7 expression in nude mice [58]. Constitutively activated STAT3 protein in melanoma could directly bind to the promoter of MMP-2 gene, thus upregulating its expression [59]. Similarly, STAT3 activation also regulated the expression of matrix metalloproteinases MMP9 and MMP-1 $[60,61]$. All these data show that STAT3 actively promotes the rate of cellular invasion.

4.4. STAT3 and Cellular Migration. Cellular migration is a central step for many biological processes, including embryogenesis, cell invasion, and cancer metastasis. Cumulative evidences has indicated the role of STAT3 in cellular migration under normal as well as pathological conditions. Sano and coworkers for the first time reported that STAT3 plays a crucial role in wound healing and cellular migration in cultured keratinocytes [62]. In SKOV3 cells, Silver and coworkers demonstrated that STAT3 signaling is required for cell motility in vitro and that depletion of STAT3 using siRNA reversed the condition, thus reducing the rate of cellular migration [63]. On the other hand, stathmin, an oncoprotein 18 , binds to $\alpha / \beta$-tubulin heterodimers and is involved in microtubule depolymerisation. $\mathrm{Ng}$ and coworkers reported that STAT3 interacts with stathmin and modulates cell migration and microtubule dynamics [64]. Similarly, loss of STAT3 expression results in a random mode of migration, while STAT3 modulates Racl activity to maintain directional persistence during migration [65]. In another work by Debidda and coworkers, the role of STAT3 is demonstrated in Rho GTPase-regulated cell migration as well as proliferation [66]. Accordingly, persistent STAT3 activation enhances migratory potential of prostate epithelial cells through integrin $\beta 6$ [67].

4.5. STAT3 and Tumor Cell Intravasation and Survival during Circulation. Following degradation of basement membrane, tumor cells enter the circulatory or lymphatic system (intravasation), survive during circulation, and extravasate into the new potent organs where they adhere to form detectable metastasis. As metastatic tumor cells enter the blood vessels, they are subjected to various nonspecific forces such as mechanical stress, hemodynamic turbulence, loss of adhesion-induced cell death, and cell mediated cytotoxicity [68]. As a result, a very low percentage of tumor cells survive during circulation which further establishes micrometastasis in distant organs. STAT3 activation has a major role in protecting the tumor cells from body's immune surveillance during their transit through circulation. Nguyen and coworkers observed that activation of STAT3 signaling in tumor cells or in inflammatory immune cells modulates secretion of various inflammatory factors such as IL6 and TNF $\alpha$ that act as an immunosuppressors, and increase the probability of survival of tumor cells [69]. Moreover, STAT3 activation in tumor microenvironment also reduces the activity of NK cells, thereby protecting tumor cells during circulation [70]. Additionally, tumor cells make association with platelets which protect them from the stresses of shear flow [71]. Thus, STAT3 activation increases the number of surviving tumor cells that invade distant potent organs to form secondary tumor.

4.6. STAT3 and Angiogenesis. Angiogenesis, the formation of new blood vessels from preexisting vasculature, is an essential step for tumor growth and metastasis. The most potent angiogenic molecule is vascular endothelial growth factor (VEGF) [72, 73]. VEGF secreted from tumor cells binds to transmembrane receptor tyrosine kinases of endothelial cells and participates in neovascularisation. STAT3 is regarded as a direct transcriptional activator of VEGF gene [74]. Niu and coworkers reported that constitutive activation of STAT3 upregulates VEGF expression and tumor angiogenesis in melanoma cells [75]. Additionally, Wei and coworkers also reported that STAT3 activation regulates VEGF expression and angiogenesis in human pancreatic cancer cells [76]. However, in contrast to this, targeting STAT3 blocks both VEGF expression and angiogenesis [77]. Besides this, various reports have also shown that STAT3 activation regulates VEGF receptor signaling in endothelial cells $[78,79]$. Inhibiting STAT3 signaling in endothelial cells prohibits their 
migration and vessel formation [79]. STAT3 has also been reported to induce expression of hypoxia-inducible factor$1 \alpha(\mathrm{HIF} 1 \alpha)$, another key mediator of angiogenesis [80]. In hypoxic conditions, both STAT3 and HIFl $\alpha$ bind simultaneously to the VEGF promoter leading to its maximum transcriptional activation and angiogenesis [81].

4.7. STAT3 and Tumor Microenvironment. Tumor cells adapt to and modify their surrounding microenvironment [82]. It is observed that tumor cells having constitutively active STAT3 signalling recruit immune cells and subvert their function for self-benefit [82]. This is achieved by increased production of immunosuppressive agents via immunosuppressive cells such as T-helper cells, dendritic cells, and macrophages and reduction in immune activation signals. STAT3 is observed to be a potent negative regulator of T1 helper cells. Several studies suggested that inhibition of STAT3 activation promotes the release of proinflammatory cytokines, while a mutant having constitutively active STAT3 in fibroblasts suppressed the LPS induced pro-inflammatory response [70, 83-85]. This suggests that STAT3 activation negatively regulates the activity of immune stimulating molecules. Dendritic cells are known to be involved in antitumor activity. However, the dendritic cells surrounding the tumor cells are partially differentiated and thus lack MHC class II molecules [86, 87]. The tumor secreted factors such as IL6, IL10, and VEGF are responsible for this partial differentiation of dendritic cells, hence reducing their antigen presenting ability [70]. Reports suggest that the tumor cells lacking STAT3 activation could efficiently produce the proinflammatory factors that promote the maturation and antigen presenting ability of dendritic cells. Apart from dendritic cells, other immune effector cells such as macrophages, neutrophils, natural killer cells, and regulatory $\mathrm{T}$ cells, in response to the growth factors released by tumor cells, show constitutive activation of STAT3, thus limiting their own ability of immune surveillance [88]. Additionally, stromal cells, in response to surrounding tumor cell secretions, upregulate their SDF-1/CXCL12 receptors which results in infiltration of endothelial progenitor cells that enhance metastatic spread of tumor cells [82]. Thus, all these enlighten the fact that STAT3 mediates a bidirectional communication with immune cells. The use of STAT inhibitors has been shown to reduce the immunosuppressive response, thus upregulating the anti-tumor ability of immune effector cells. Although STAT3 is considered as a primary target to overcome immunosuppression, more recently other signal transduction pathways such as MAPKs have also attracted attention in order to prevent immunosuppression.

\section{STAT3 Inhibitors: Translational Advances}

STAT3 is excessively active in many cancers and plays a central role in tumorigenesis. Several lines of evidence have implicated that inhibition of STAT3 with a dominant negative form of STAT3 or other inhibitors attenuates the proliferation and survival of a wide variety of cancers with little or no effects on normal cells [12]. While inactivation of STAT3 leads to embryonic lethality in mice, its function is dispensable in many adult tissues. Collectively, these lines of evidence have validated STAT3 as a target for cancer therapy. Several molecules have been identified that can block STAT3 activation in a variety of preclinical models both in vitro and in vivo (Table 2). These include the following.

5.1. Curcumin. Curcumin, an active component of turmeric, has been demonstrated to have anticancerous, anti-inflammatory, and antioxidant properties. Curcumin inhibits STAT3 activation in various cell lines including multiple myeloma [89], pancreatic cancer cell lines [90], Hodgkin's lymphoma [91], head and neck squamous cell carcinoma [92], primary effusion lymphoma [93], human chronic myelogenous leukaemia [94] and ovarian cancer [95]. Further, a small molecule curcumin analog, FLLL32, induces apoptosis in melanoma cells via STAT3 inhibition without altering STAT1 signaling [96].

5.2. Resveratrol. Resveratrol (3,5,4'-trihydroxystilbene), a naturally occurring polyphenolic phytoalexin has antiinflammatory and anti-oxidant properties. Jang and coworkers reported that resveratrol treatment inhibited the development of preneoplastic lesions in carcinogen-treated mouse mammary glands in culture and tumorigenesis in a mouse skin cancer model [97]. Further mechanistic studies revealed that resveratrol inhibited tumor growth and induced apoptosis by suppressing STAT3 signaling. Additionally, Kotha and coworkers reported that resveratrol inhibited Src and STAT3 signaling and induced apoptosis of malignant cells (NIH3T3/v-Src fibroblasts, human breast cancer MDA-MB468 and MDA-MB-231, prostate cancer DU145, or human pancreatic cancer Panc-1 and Colo-357) containing activated STAT3 protein [98]. Other reports show that resveratrol inhibits STAT3 activation in many other cancer cell lines including multiple myeloma [99], endothelial cells [100], medulloblastoma [101], and glioblastoma [102].

5.3. Flavopiridol. Flavopiridol, a flavonoid derived from an Indian plant, is a potent cyclin-dependent kinase inhibitor [103]. At higher concentrations, it inhibits the activity of receptor tyrosine kinases (EGFR), receptor associates tyrosine kinases (pp60 Src), and signal transducing kinases (PKC and Erk-1) [103]. Flavopiridol induces apoptosis in many human cancer cell lines in vitro and has potent antitumor activity in vivo against human leukemia and lymphoma xenografts $[104,105]$. Studies by Lee and coworkers demonstrated that flavopiridol disrupts STAT3/DNA interaction, attenuates STAT3 directed transcription, and downregulates Mcl1, an antiapoptotic protein present downstream of STAT3 [104]. Flavopiridol in combination with bortezomib also inhibits activity of STAT3 and STAT5 and induces apoptosis in chronic myeloid leukemia [106].

5.4. Cucurbitacin Derivatives. Cucurbitacin, and their derivatives are triterpenoid compounds isolated from various plant families, such as Cruciferae or Cucurbitaceae. They exhibit diverse biological activities including anti-inflammatory and anticancer effects. Several cucurbitacin derivatives 
TABLE 2: Small molecule STAT3 inhibitors and their structure.

STAT3 inhibitor

(3) Cucurbitacin derivatives Structure of various cucurbitacin derivatives

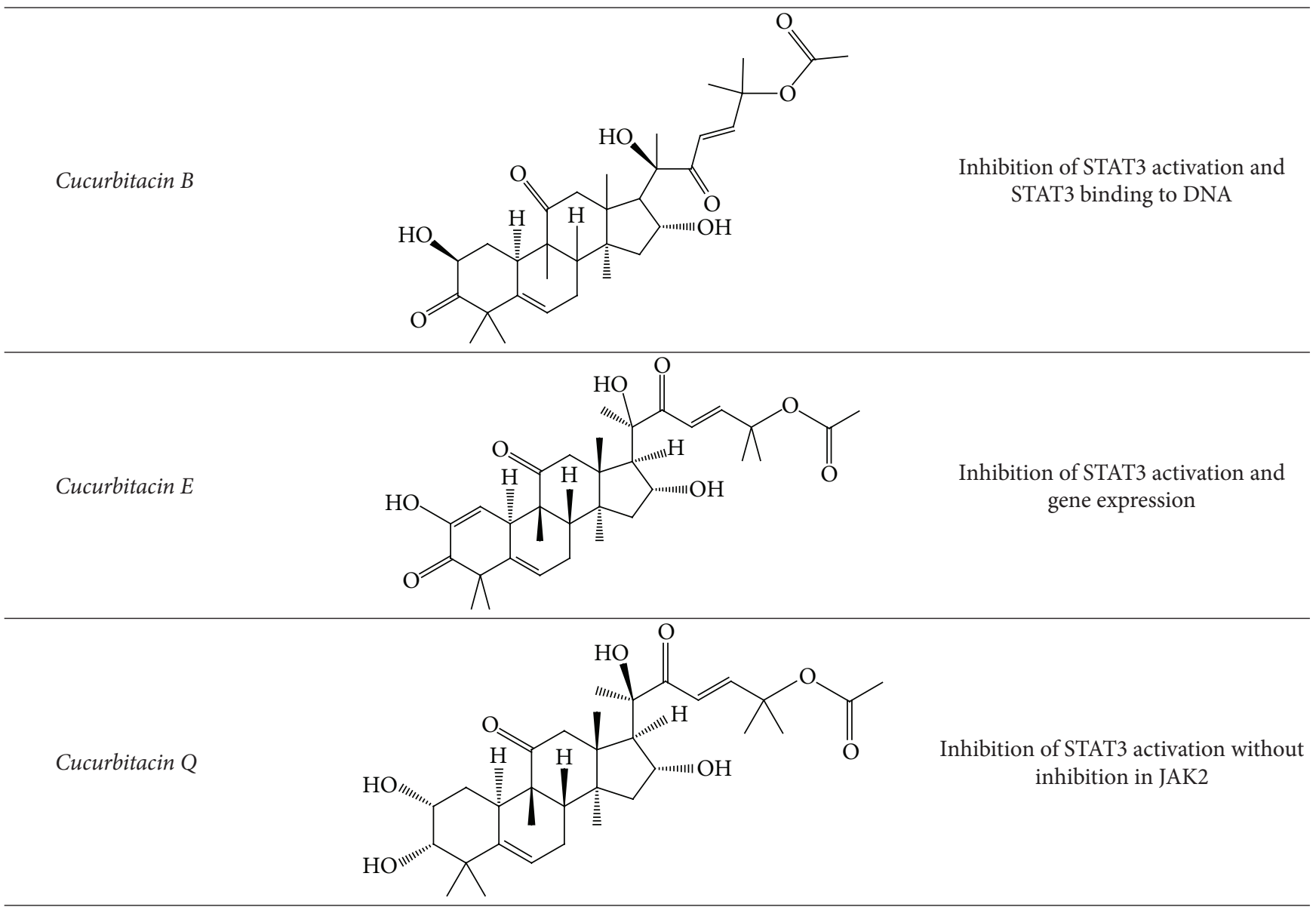


TABLe 2: Continued.

STAT3 inhibitor

(5) Deoxytetrangomycin<smiles>C[C@H]1CC(=O)c2c(ccc3c2C(=O)c2cccc(O)c2C3=O)C1</smiles>

Abrogates STAT3 dimerization, STAT3 nuclear translocation and STAT3 DNA binding<smiles>CCCCCCCC(=O)CC(=O)NC1CCOC1=O</smiles>

Inhibits tyrosine phosphorylation of STAT3, STAT1 and serine phosphorylation of STAT3<smiles>[R]C(=O)NC1CCOC1=O</smiles>

Inhibition of STAT3 activation

(7) N-Acyl homoserine lactone Structure of various indirubin derivatives

Mechanism of inhibition

(8) Indirubin derivatives<smiles>O=CCC(O)CO</smiles>

E804<smiles>O=C1Nc2ccccc2/C1=C1/Nc2ccccc2/C1=N/O</smiles>

Inhibition of STAT3 activation and STAT3 gene expression

6-Bromoindirubin-3-oxime<smiles>O=C1Nc2cc(Br)ccc2/C1=C1\Nc2ccccc2\C1=N\O</smiles>

Inhibition of STAT3 activation and STAT3 gene expression 
TABLE 2: Continued.

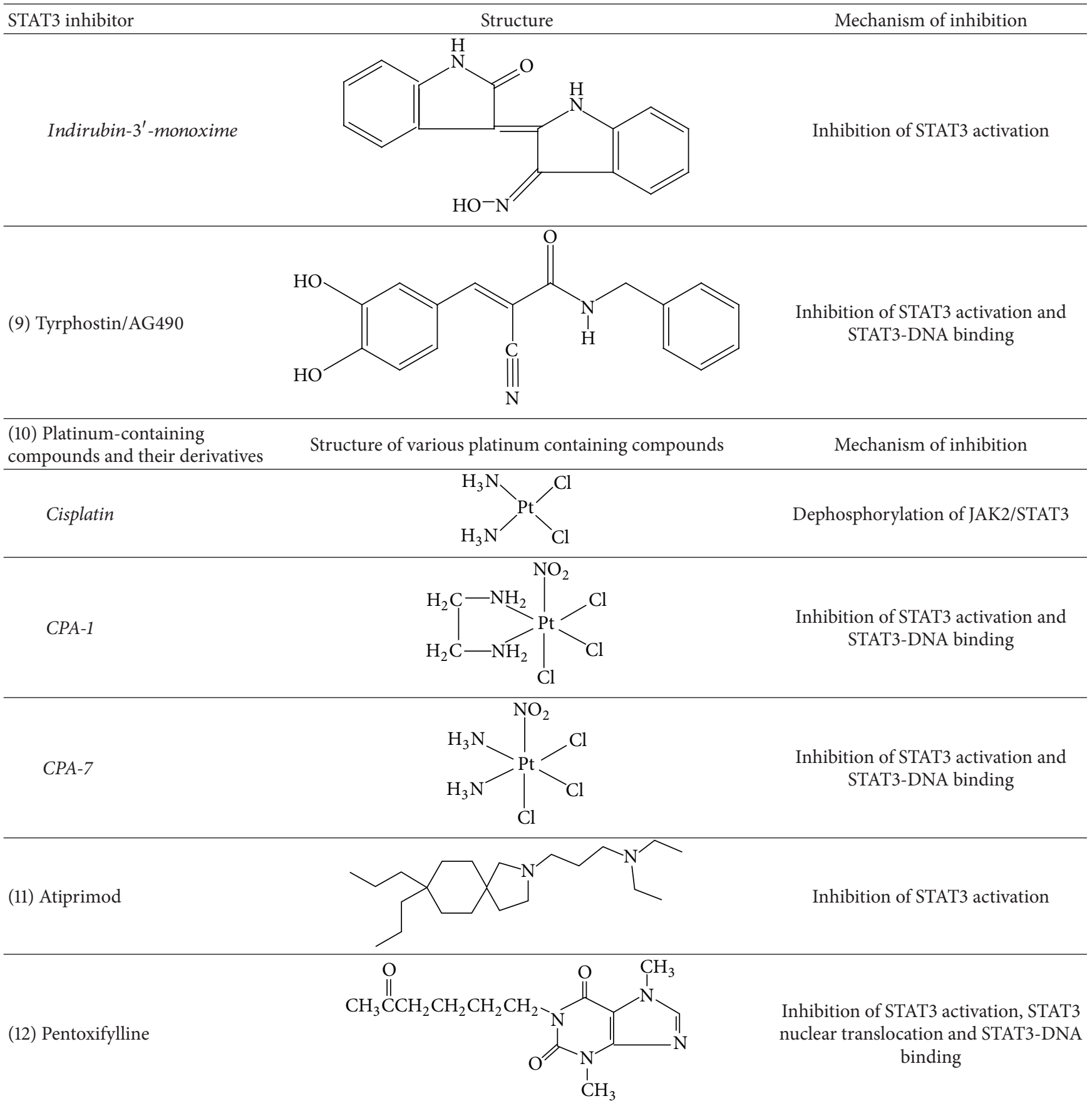

have been reported to show their effect on STAT3 signaling. JSI-124, previously identified as cucurbitacin I, reduced the levels of phosphotyrosine of constitutively activated STAT3 in many human cancer cell lines including lung and breast carcinomas [107, 108]. Cucurbitacin B, another derivative suppresses tumor growth in pancreatic cancer cells by inhibiting JAK/STAT pathway and synergistically increases antiproliferative effects of gemcitabine in vitro [109]. Cucurbitacin Q also inhibits STAT3 activation and induces apoptosis without inhibiting JAK2, Src, Akt, Erk, or JNK activation in human and murine tumors that contain constitutively activated STAT3 (i.e., A549, MDA-MB-435, and v-Src/NIH 3T3) [110]. Cucurbitacin E inhibits STAT3/p53/p21 signaling and induces apoptosis via Fas/CD95 and mitochondriadependent pathways in human bladder cancer T24 cells [111].

5.5. Deoxytetrangomycin. Deoxytetrangomycin or STA1 was discovered by structure-based virtual database screening of the National Cancer Institute (NCI) database. It inhibits STAT3 dimerization, STAT3 nuclear translocation, STAT3 
TABLE 3: Selected JAK inhibitors currently being evaluated in clinical trials for autoimmunity and cancer.

\begin{tabular}{|c|c|c|}
\hline Inhibitor & $\begin{array}{l}\text { Targeted } \\
\text { JAK }\end{array}$ & Phase in development \\
\hline Ruxolitinib & JAK2, JAK1 & $\begin{array}{l}\text { FDA approved for myelofibrosis } \\
\text { Phase II in prostate cancer, } \\
\text { hematological malignances }\end{array}$ \\
\hline Tofacitinib & JAK3, JAK1 & $\begin{array}{l}\text { FDA approved for rheumatoid } \\
\text { arthritis }\end{array}$ \\
\hline SAR302503 & JAK2, JAK1 & $\begin{array}{l}\text { Phase I in solid tumors } \\
\text { Phase III in myelofibrosis }\end{array}$ \\
\hline CYT387 & JAK2, JAK1 & Phase II in myelofibrosis \\
\hline Pacritinib & JAK2 & Phase II in hematologic malignancies \\
\hline AZD1480 & JAK2, JAK1 & Phase I in solid tumors \\
\hline INCB028050 & JAK2, JAK1 & Phase II in rheumatoid arthritis \\
\hline
\end{tabular}

TABLE 4: Selected JAK inhibitors in preclinical stage.

\begin{tabular}{lcc}
\hline Inhibitor & Targeted JAK & Indication \\
\hline BMS-911543 & JAK2 & Myelofibrosis \\
AC-430 & JAK2 & Rheumatoid arthritis, lymphoma \\
CEP-33779 & JAK2 & Rheumatoid arthritis \\
R723 & JAK2 & Myeloproliferative neoplasias \\
\hline
\end{tabular}

DNA binding, and STAT3-dependent luciferase activity in MDA-MB-435s breast cancer cells [112].

5.6. Cyclopentenone Derivatives. Weidler and coworkers identified CPDHC(1), a novel cyclopentenone derivative as an inhibitor of IL6 dependent JAK/STAT pathway while screening fungal extracts with a cell based reporter assay [113]. CPDHC(1) inhibits STAT3 and STAT1 tyrosine phosphorylation and STAT3 serine phosphorylation in HepG2 cells [113].

5.7. N-Acyl Homoserine Lactone. N-Acyl homoserine lactones are a class of signaling molecules involved in bacterial quorum sensing [114]. The quorum-sensing signal molecule of $P$. aeruginosa, N-(3-oxododecanoyl)-L-homoserine lactone $(\mathrm{OdDHL})$, has been reported to modulate inflammation and immune responses in mammals. In addition, $\mathrm{Li}$ and coworkers reported that OdDHL blocks proliferation and induces apoptosis in human breast cancer cell lines such as BR293, MCF-7, and MDA-MB-468 [115]. Further studies on the mode of action of OdHL revealed that it has no significant effect on MAPK cascades, partially inhibits the Akt/PKB pathway, and suppresses STAT3 activity [115].

5.8. Indirubin Derivatives. Indirubin, an active constituent of a Chinese herbal medicine, is used for the treatment of chronic myelogenous leukemia and has been shown to be a potent inhibitor of cyclin dependent kinases [116]. Reports suggest that indirubin or its derivatives inhibit cellular proliferation and induce apoptosis in many human cancers [117]. Nam and coworkers reported that indirubin derivative E804 suppressed STAT3 tyrosine phosphorylation by inhibiting upstream cSrc kinase activity [118]. The antiapoptotic proteins Mcl-1 and survivin were downregulated upon E804 treatment followed by induction of apoptosis in human breast cancer cells [118]. Apart from E804, 6-bromoindirubin-3-oxime, a bromo derivative of indirubin selectively inhibits JAK/STAT3 signaling in human melanoma cells [119]. Similarly, indirubin-3'-monoxime, a chemical derivative of indirubin, was found to inhibit phosphorylation of STAT3 and STAT1 by blocking the activity of the FGFR1 tyrosine kinase in myeloid leukemia cell line KGla [120].

5.9. Tyrphostins. Tyrphostins represent a novel class of selective protein tyrosine kinase inhibitors that have antitumor activity both in vitro and in vivo. $\mathrm{Ni}$ and coworkers reported that Janus kinase inhibitor, tyrphostin AG490, inhibited the constitutive activation of STAT3 and suppressed the growth of human prostate cancer cells [121]. AG490 also inhibits STAT3 signaling in multiple myeloma [122] and Hodgkins lymphoma [123]. Similarly, Nielsen and coworkers showed that AG490 blocked the constitutive activation of STAT3 and inhibited both spontaneous and interleukin 2-induced growth of mycosis fungoides tumor cells [124]. Another analogue of tyrphostin, AG17, inhibited STAT3 phosphorylation and induced apoptosis in classical Hodgkin lymphoma cells [125].

5.10. JAK Inhibitors. JAK/STAT3 signaling is deregulated in majority of human cancers and promotes tumor growth and metastasis. While direct inhibition of STAT3 by small molecule inhibitors is difficult, targeting JAK kinases by using their inhibitors is one of the approaches to inhibit STAT3 signaling. JAK family of kinases comprises four members JAK1, JAK2, JAK3, and TYK2. Various JAK inhibitors have been tested in clinical trials for patients with myelofibrosis and other diseases such as cancer (Table 3). Ruxolitinib, an oral JAK1 and JAK2 inhibitor, is the first JAK inhibitor that has been approved by the FDA for the treatment of myelofibrosis [126]. Currently, ruxolitinib is also in phase II trials for the treatment of haematological malignancies and prostate cancer [127]. Another JAK inhibitor, SAR302503, is currently in phase I clinical trial for the treatment of solid tumors. Pacritinib, a JAK2 inhibitor is in a phase III trial to treat myelofibrosis and in several phase I/II trials in other hematologic malignancies [128]. Another JAK2 inhibitor AZD1480 potently blocks STAT3 signaling and, currently in phase I trial in treatment of solid tumors [129]. Other JAK inhibitors such as BMS-911543, AC-430, and CEP-33779 are either in preclinical stages or in early stages of development (Table 4).

5.11. Platinum-Containing Compounds. Platinum-containing compounds such as cisplatin, carboplatin, and oxaliplatin are among the most widely used chemotherapeutic drugs. The mechanism of action of these drugs involves cross linking to purine DNA bases, which leads to apoptosis [130]. It regulates 
several signaling pathways such as MAPK and PI3K/Akt [131]. Song and coworkers reported that cisplatin inhibits JAK2/STAT3 signaling in cancer cells [132]. Other novel platinum containing complexes were also identified and reported as STAT3 inhibitors. The novel platinum-containing compounds such as CPA-1 and CPA-7 inhibit STAT3 signaling and suppress its biological functions in malignant cells that harbour constitutive STAT3 expression [133]. Another platinum (IV) compound, IS3 295, selected from the NCI diversity set appears to have STAT3 inhibitor activity [134]. Results suggested that IS3 295 selectively inhibits STAT3 signaling pathway, thereby inducing cell cycle arrest at G0/G1 phase and apoptosis [134].

5.12. Atiprimod. Atiprimod is a small molecule that belongs to the azaspirane class of drugs. They are cationic amphiphilic agents that exhibit anti-inflamatory, antiproliferative, and antiangiogenic properties. Choudhari and coworkers have shown that atiprimod inhibits protein kinase B (Akt) and STAT3 signaling, thereby inhibiting proliferation and inducing apoptosis in hepatocellular carcinoma [135]. Atiprimod was also found to be involved in inhibiting STAT3 phosphorylation and inducing apoptosis in multiple myeloma cells U266-B1 [136]. In mantle cell lymphoma (MCL), atiprimod was responsible for induction of apoptosis via mitochondrial pathway [137]. A mechanistic study revealed that atiprimod treatment activates JNK signaling and inhibits NFKB and STAT3 activities in MCL cells [137]. Similarly, in acute myeloid leukemia, atiprimod inhibits proliferation and induces apoptosis by suppressing STAT3 and STAT5 phosphorylation [138].

5.13. Pentoxifylline. Pentoxifylline (PTX), a methyl xanthine derivative, is a FDA approved drug for treatment of peripheral vascular disease [139]. It is a nonspecific phosphodiesterase inhibitor that elevates cAMP in the cells and exhibits potent antimetastatic and antiangiogenic activities against many human cancers in vitro as well as in vivo [140]. PTX at subtoxic doses inhibits proliferation, migration, and invasion of A375 human melanoma cells in vitro and tumor growth in vivo [140]. Further mechanistic study revealed that PTX inhibits STAT3 phosphorylation and DNA binding in melanoma cells and that this inhibition was partly mediated through the inhibition of upstream kinases pJAK1 and pJak2 [141]. PTX has also been shown to inhibit STAT3 phosphorylation in B16F10 melanoma and A549 lung carcinoma (our unpublished data).

5.14. STAT3 Decoy Oligonucleotide. STAT3 decoy comprises a 15 bp double-stranded oligonucleotide, which corresponds closely to the STAT3 response element in the c-fos promoter and binds competitively to STAT3 [142]. STAT3 decoy inhibited proliferation and STAT3 mediated gene expression in squamous cell carcinoma of the head and neck in vitro as well as in a xenograft model in vivo [142, 143]. Sen and coworkers conducted first phase 0 clinical trial using STAT3 decoy in head and neck cancer and reported that intratumoral administration of STAT3 decoy oligonucleotide abrogates target gene expression in patients with head and neck squamous cell carcinoma [144]. STAT3 decoy has also been shown to inhibit the growth of human lung cancer and glioma $[145,146]$.

\section{Conclusion and Future Perspectives}

Although in normal cells STAT3 expression is very transient and tightly regulated, its persistent activation has been confirmed clinically in majority of tumor samples. This persistent STAT3 activation plays a central role in tumorigenesis and provides favourable conditions to the tumor cells to undergo metastasis while being involved in cellular proliferation, invasion, migration, and angiogenesis. In contrast to this, blocking STAT3 signaling in tumor cells inhibits tumor growth, angiogenesis, and metastasis without affecting normal cells, thus confirming STAT3 as a potential target for cancer therapy. Despite the different approaches to identify small molecules that effectively inhibit STAT3 signaling, further studies will be needed to make these molecules more effective for improved clinical outcomes. We believe that this is possible by using interdisciplinary approaches of rational drug design and/or high throughput screening or by optimization of various combination therapies.

\section{Conflict of Interests}

The authors declare that they have no conflict of interests.

\section{Acknowledgments}

The authors acknowledge the grant support from ACTREC, Tata Memorial Centre. Mr. M. Z. Kamran is supported by the Indian Council of Medical Research (ICMR) Senior Research Fellowship. The authors thank Kavita Shirsath for contribution in Figure 1.

\section{References}

[1] S. Akira, Y. Nishio, M. Inoue et al., "Molecular cloning of APRF, a novel IFN-stimulated gene factor 3 p91-related transcription factor involved in the gp130-mediated signaling pathway," Cell, vol. 77, no. 1, pp. 63-71, 1994.

[2] J. E. Darnell Jr., I. M. Kerr, and G. R. Stark, "Jak-STAT pathways and transcriptional activation in response to IFNs and other extracellular signaling proteins," Science, vol. 264, no. 5164, pp. 1415-1421, 1994.

[3] J. E. Darnell Jr., "STATs and gene regulation," Science, vol. 277, no. 5332, pp. 1630-1635, 1997.

[4] D. E. Levy, "Physiological significance of STAT proteins: investigations through gene disruption in vivo," Cellular and Molecular Life Sciences, vol. 55, no. 12, pp. 1559-1567, 1999.

[5] N. G. Copeland, D. J. Gilbert, C. Schindler et al., "Distribution of the mammalian stat gene family in mouse chromosomes," Genomics, vol. 29, no. 1, pp. 225-228, 1995.

[6] J. N. Ihle, "The Stat family in cytokine signaling," Current Opinion in Cell Biology, vol. 13, no. 2, pp. 211-217, 2001.

[7] Z. Wen and J. E. Darnell Jr., "Mapping of Stat3 serine phosphorylation to a single residue (727) and evidence that serine 
phosphorylation has no influence on DNA binding of Statl and Stat3," Nucleic Acids Research, vol. 25, no. 11, pp. 2062-2067, 1997.

[8] K. Yokogami, S. Wakisaka, J. Avruch, and S. A. Reeves, "Serine phosphorylation and maximal activation of STAT3 during CNTF signaling is mediated by the rapamycin target mTOR," Current Biology, vol. 10, no. 1, pp. 47-50, 2000.

[9] T. Bowman, R. Garcia, J. Turkson, and R. Jove, "STATs in oncogenesis," Oncogene, vol. 19, no. 21, pp. 2474-2488, 2000.

[10] R. Buettner, L. B. Mora, and R. Jove, "Activated STAT signaling in human tumors provides novel molecular targets for therapeutic intervention," Clinical Cancer Research, vol. 8, no. 4, pp. 945-954, 2002.

[11] S. Huang, "Regulation of metastases by signal transducer and activator of transcription 3 signaling pathway: clinical implications," Clinical Cancer Research, vol. 13, no. 5, pp. 13621366, 2007.

[12] G. Niu, R. Heller, R. Catlett-Falcone et al., "Gene therapy with dominant-negative Stat3 suppresses growth of the murine melanoma B16 tumor in vivo," Cancer Research, vol. 59, no. 20, pp. 5059-5063, 1999.

[13] R. Garcia, C.-L. Yu, A. Hudnall et al., "Constitutive activation of Stat3 in fibroblasts transformed by diverse oncoproteins and in breast carcinoma cells," Cell Growth and Differentiation, vol. 8, no. 12, pp. 1267-1276, 1997.

[14] D. W. Leaman, S. Leung, X. Li, and G. R. Stark, "Regulation of STAT-dependent pathways by growth factors and cytokines," FASEB Journal, vol. 10, no. 14, pp. 1578-1588, 1996.

[15] C.-L. Yu, D. J. Meyer, G. S. Campbell et al., "Enhanced DNAbinding activity of a Stat3-related protein in cells transformed by the Src oncoprotein," Science, vol. 269, no. 5220, pp. 81-83, 1995.

[16] R. L. Ilaria Jr. and R. A. Van Etten, "P210 and P190(BCR/ABL) induce the tyrosine phosphorylation and DNA binding activity of multiple specific STAT family members," Journal of Biological Chemistry, vol. 271, no. 49, pp. 31704-31710, 1996.

[17] J. Turkson, T. Bowman, J. Adnane et al., "Requirement for Ras/Racl-mediated p38 and c-Jun N-terminal kinase signaling in Stat 3 transcriptional activity induced by the Src oncoprotein," Molecular and Cellular Biology, vol. 19, no. 11, pp. 7519-7528, 1999.

[18] J. Chung, E. Uchida, T. C. Grammer, and J. Blenis, "STAT3 serine phosphorylation by ERK-dependent and -independent pathways negatively modulates its tyrosine phosphorylation," Molecular and Cellular Biology, vol. 17, no. 11, pp. 6508-6516, 1997.

[19] N. Jain, T. Zhang, W. H. Kee, W. Li, and X. Cao, "Protein kinase $\mathrm{C} \delta$ associates with and phosphorylates Stat 3 in an interleukin6-dependent manner," Journal of Biological Chemistry, vol. 274, no. 34, pp. 24392-24400, 1999.

[20] H. Kojima, T. Sasaki, T. Ishitani et al., "STAT3 regulates Nemolike kinase by mediating its interaction with IL-6-stimulated TGF $\beta$-activated kinase 1 for STAT3 Ser-727 phosphorylation," Proceedings of the National Academy of Sciences of the United States of America, vol. 102, no. 12, pp. 4524-4529, 2005.

[21] Z.-L. Yuan, Y.-J. Guan, D. Chatterjee, and Y. E. Chin, "Stat3 dimerization regulated by reversible acetylation of a single lysine residue," Science, vol. 307, no. 5707, pp. 269-273, 2005.

[22] W. Chen, M. O. Daines, and G. K. Khurana Hershey, “Turning off signal transducer and activator of transcription (STAT): the negative regulation of STAT signaling," Journal of Allergy and Clinical Immunology, vol. 114, no. 3, pp. 476-489, 2004.
[23] B. G. Neel and N. K. Tonks, "Protein tyrosine phosphatases in signal transduction," Current Opinion in Cell Biology, vol. 9, no. 2, pp. 193-204, 1997.

[24] J. N. Andersen, O. H. Mortensen, G. H. Peters et al., "Structural and evolutionary relationships among protein tyrosine phosphatase domains," Molecular and Cellular Biology, vol. 21, no. 21, pp. 7117-7136, 2001.

[25] J. Irie-Sasaki, T. Sasaki, W. Matsumoto et al., "CD45 is a JAK phosphatase and negatively regulates cytokine receptor signalling," Nature, vol. 409, no. 6818, pp. 349-354, 2001.

[26] Y. Han, H. M. Amin, B. Franko, C. Frantz, X. Shi, and R. Lai, "Loss of SHP1 enhances JAK3/STAT3 signaling and decreases proteosome degradation of JAK3 and NPM-ALK in $\mathrm{ALK}^{+}$ anaplastic large-cell lymphoma," Blood, vol. 108, no. 8, pp. 27962803, 2006.

[27] E. A. Bard-Chapeau, S. Li, J. Ding et al., "Ptpn11/Shp2 acts as a tumor suppressor in hepatocellular carcinogenesis," Cancer Cell, vol. 19, no. 5, pp. 629-639, 2011.

[28] H. Liang, V. J. Venema, X. Wang, H. Ju, R. C. Venema, and M. B. Marrero, "Regulation of angiotensin II-induced phosphorylation of STAT3 in vascular smooth muscle cells," Journal of Biological Chemistry, vol. 274, no. 28, pp. 19846-19851, 1999.

[29] S. Rigacci, D. Talini, and A. Berti, "LMW-PTP associates and dephosphorylates STAT5 interacting with its C-terminal domain," Biochemical and Biophysical Research Communications, vol. 312, no. 2, pp. 360-366, 2003.

[30] K. Shuai and B. Liu, "Regulation of gene-activation pathways by pias proteins in the immune system," Nature Reviews Immunology, vol. 5, no. 8, pp. 593-605, 2005.

[31] K. Shuai, "Modulation of STAT signaling by STAT-interacting proteins," Oncogene, vol. 19, no. 21, pp. 2638-2644, 2000.

[32] B. Liu, J. Liao, X. Rao et al., "Inhibition of Statl-mediated gene activation by PIAS1," Proceedings of the National Academy of Sciences of the United States of America, vol. 95, no. 18, pp. 1062610631, 1998.

[33] C. D. Chung, J. Liao, B. Liu et al., "Specific inhibition of Stat3 signal transduction by PIAS3," Science, vol. 278, no. 5344, pp. 1803-1805, 1997.

[34] B. Liu, M. Gross, J. Ten Hoeve, and K. Shuai, "A transcriptional corepressor of Statl with an essential LXXLL signature motif," Proceedings of the National Academy of Sciences of the United States of America, vol. 98, no. 6, pp. 3203-3207, 2001.

[35] T. Arora, B. Liu, H. He et al., "PIASx is a transcriptional corepressor of signal transducer and activator of transcription 4," Journal of Biological Chemistry, vol. 278, no. 24, pp. 21327-21330, 2003.

[36] T. Naka, M. Narazaki, M. Hirata et al., "Structure and function of a new STAT-induced STAT inhibitor," Nature, vol. 387, no. 6636, pp. 924-929, 1997.

[37] T. A. Endo, M. Masuhara, M. Yokouchi et al., "A new protein containing an SH2 domain that inhibits JAK kinases," Nature, vol. 387, no. 6636, pp. 921-924, 1997.

[38] R. Starr, T. A. Willson, E. M. Viney et al., "A family of cytokineinducible inhibitors of signalling," Nature, vol. 387, no. 6636, pp. 917-921, 1997.

[39] B. A. Croker, H. Kiu, and S. E. Nicholson, "SOCS regulation of the JAK/STAT signalling pathway," Seminars in Cell and Developmental Biology, vol. 19, no. 4, pp. 414-422, 2008.

[40] J.-G. Zhang, A. Farley, S. E. Nicholson et al., "The conserved SOCS box motif in suppressors of cytokine signaling binds 
to elongins $\mathrm{B}$ and $\mathrm{C}$ and may couple bound proteins to proteasomal degradation," Proceedings of the National Academy of Sciences of the United States of America, vol. 96, no. 5, pp. 2071-2076, 1999.

[41] J. F. Bromberg, M. H. Wrzeszczynska, G. Devgan et al., "Stat3 as an oncogene," Cell, vol. 98, no. 3, pp. 295-303, 1999.

[42] J. Turkson, T. Bowman, R. Garcia, E. Caldenhoven, R. P. De Groot, and R. Jove, "Stat 3 activation by Src induces specific gene regulation and is required for cell transformation," Molecular and Cellular Biology, vol. 18, no. 5, pp. 2545-2552, 1998.

[43] C.-Y. Yu, L. Wang, A. Khaletskiy et al., "STAT3 activation is required for interleukin-6 induced transformation in tumorpromotion sensitive mouse skin epithelial cells," Oncogene, vol. 21, no. 25, pp. 3949-3960, 2002.

[44] C. Miranda, T. Fumagalli, M. C. Anania et al., "Role of STAT3 in in vitro transformation triggered by TRK oncogenes," PLoS One, vol. 5, no. 3, Article ID e9446, 2010.

[45] J. H. Hwang, D. W. Kim, J. M. Suh et al., "Activation of signal transducer and activator of transcription 3 by oncogenic RET/PTC (rearranged in transformation/papillary thyroid carcinoma) tyrosine kinase: roles in specific gene regulation and cellular transformation," Molecular Endocrinology, vol. 17, no. 6, pp. 1155-1166, 2003.

[46] T. Yoshida, T. Hanada, T. Tokuhisa et al., "Activation of STAT3 by the hepatitis $\mathrm{C}$ virus core protein leads to cellular transformation," Journal of Experimental Medicine, vol. 196, no. 5, pp. 641-653, 2002.

[47] A. Vultur, R. Arulanandam, J. Turkson, G. Niu, R. Jove, and L. Raptis, "Stat3 is required for full neoplastic transformation by the simian virus 40 large tumor antigen," Molecular Biology of the Cell, vol. 16, no. 8, pp. 3832-3846, 2005.

[48] Y.-H. Chung, N.-H. Cho, M. I. Garcia, S.-H. Lee, P. Feng, and J. U. Jung, "Activation of Stat3 transcription factor by Herpesvirus Saimiri STP-A oncoprotein," Journal of Virology, vol. 78, no. 12, pp. 6489-6497, 2004.

[49] D. A. Frank, "STAT3 as a central mediator of neoplastic cellular transformation," Cancer Letters, vol. 251, no. 2, pp. 199-210, 2007.

[50] C. V. Dang, "c-Myc target genes involved in cell growth, apoptosis, and metabolism," Molecular and Cellular Biology, vol. 19, no. 1, pp. 1-11, 1999.

[51] T. Shirogane, T. Fukada, J. M. M. Muller, D. T. Shima, M. Hibi, and T. Hirano, "Synergistic roles for Pim-1 and c-Myc in STAT3mediated cell cycle progression and antiapoptosis," Immunity, vol. 11, no. 6, pp. 709-719, 1999.

[52] S. Bhattacharya, R. M. Ray, and L. R. Johnson, "STAT3mediated transcription of Bcl-2, Mcl-1 and C-IAP2 prevents apoptosis in polyamine-depleted cells," Biochemical Journal, vol. 392, part 2, pp. 335-344, 2005.

[53] G. Niu, K. L. Wright, Y. Ma et al., "Role of Stat3 in regulating p53 expression and function," Molecular and Cellular Biology, vol. 25, no. 17, pp. 7432-7440, 2005.

[54] R. S. Chapman, P. C. Lourenco, E. Tonner et al., "Suppression of epithelial apoptosis and delayed mammary gland involution in mice with a conditional knockout of Stat3," Genes and Development, vol. 13, no. 19, pp. 2604-2616, 1999.

[55] N. De La Iglesia, G. Konopka, S. V. Puram et al., "Identification of a PTEN-regulated STAT3 brain tumor suppressor pathway," Genes and Development, vol. 22, no. 4, pp. 449-462, 2008.
[56] C. Suiqing, Z. Min, and C. Lirong, "Overexpression of phosphorylated-STAT3 correlated with the invasion and metastasis of cutaneous squamous cell carcinoma," Journal of Dermatology, vol. 32, no. 5, pp. 354-360, 2005.

[57] Z. Qiu, C. Huang, J. Sun et al., "RNA interference-mediated signal transducers and activators of transcription 3 gene silencing inhibits invasion and metastasis of human pancreatic cancer cells," Cancer Science, vol. 98, no. 7, pp. 1099-1106, 2007.

[58] H. D. Li, C. Huang, K. J. Huang et al., "STAT3 knockdown reduces pancreatic cancer cell invasiveness and matrix metalloproteinase-7 expression in nude mice," PLoS One, vol. 6, no. 10, Article ID e25941, 2011.

[59] T.-X. Xie, D. Wei, M. Liu et al., "Stat3 activation regulates the expression of matrix metalloproteinase- 2 and tumor invasion and metastasis," Oncogene, vol. 23, no. 20, pp. 3550-3560, 2004.

[60] T. N. Dechow, L. Pedranzini, A. Leitch et al., "Requirement of matrix metalloproteinase- 9 for the transformation of human mammary epithelial cells by Stat3-C," Proceedings of the National Academy of Sciences of the United States of America, vol. 101, no. 29, pp. 10602-10607, 2004.

[61] M. Itoh, T. Murata, T. Suzuki et al., "Requirement of STAT3 activation for maximal collagenase-1 (MMP-1) induction by epidermal growth factor and malignant characteristics in T24 bladder cancer cells," Oncogene, vol. 25, no. 8, pp. 1195-1204, 2006.

[62] S. Sano, S. Itami, K. Takeda et al., "Keratinocyte-specific ablation of Stat 3 exhibits impaired skin remodeling, but does not affect skin morphogenesis," The EMBO Journal, vol. 18, no. 17, pp. 4657-4668, 1999.

[63] D. L. Silver, H. Naora, J. Liu, W. Cheng, and D. J. Montell, "Activated signal transducer and activator of transcription (STAT) 3: localization in focal adhesions and function in ovarian cancer cell motility," Cancer Research, vol. 64, no. 10, pp. 3550-3558, 2004.

[64] D. C. H. Ng, H. L. Bao, P. L. Cheh et al., "Stat3 regulates microtubules by antagonizing the depolymerization activity of stathmin," Journal of Cell Biology, vol. 172, no. 2, pp. 245-257, 2006.

[65] T. S. Teng, B. Lin, E. Manser, D. C. H. Ng, and X. Cao, "Stat3 promotes directional cell migration by regulating Racl activity via its activator $\beta$ PIX," Journal of Cell Science, vol. 122, no. 22, pp. 4150-4159, 2009.

[66] M. Debidda, L. Wang, H. Zang, V. Poli, and Y. Zheng, "A role of STAT3 in Rho GTPase-regulated cell migration and proliferation," Journal of Biological Chemistry, vol. 280, no. 17, pp. 17275-17285, 2005.

[67] J. Azare, K. Leslie, H. Al-Ahmadie et al., "Constitutively activated stat 3 induces tumorigenesis and enhances cell motility of prostate epithelial cells through integrin $\beta 6$," Molecular and Cellular Biology, vol. 27, no. 12, pp. 4444-4453, 2007.

[68] P. Gassmann and J. Haier, "The tumor cell-host organ interface in the early onset of metastatic organ colonisation," Clinical and Experimental Metastasis, vol. 25, no. 2, pp. 171-181, 2008.

[69] D. X. Nguyen, P. D. Bos, and J. Massagué, "Metastasis: from dissemination to organ-specific colonization," Nature Reviews Cancer, vol. 9, no. 4, pp. 274-284, 2009.

[70] T. Wang, G. Niu, M. Kortylewski et al., "Regulation of the innate and adaptive immune responses by Stat-3 signaling in tumor cells," Nature Medicine, vol. 10, no. 1, pp. 48-54, 2004.

[71] O. J. T. McCarty, S. A. Mousa, P. F. Bray, and K. Konstantopoulos, "Immobilized platelets support human colon carcinoma cell 
tethering, rolling, and firm adhesion under dynamic flow conditions," Blood, vol. 96, no. 5, pp. 1789-1797, 2000.

[72] J. Grunstein, W. G. Roberts, O. Mathieu-Costello, D. Hanahan, and R. S. Johnson, "Tumor-derived expression of vascular endothelial growth factor is a critical factor in tumor expansion and vascular function," Cancer Research, vol. 59, no. 7, pp. 15921598, 1999.

[73] K. H. Plate, G. Breier, H. A. Weich, and W. Risau, "Vascular endothelial growth factor is a potential tumour angiogenssis factor in human gliomas in vivo," Nature, vol. 359, no. 6398, pp. 845-848, 1992.

[74] Z. Chen and C. H. Zhong, "STAT3: a critical transcription activator in angiogenesis," Medicinal Research Reviews, vol. 28, no. 2, pp. 185-200, 2008.

[75] G. Niu, K. L. Wright, M. Huang et al., "Constitutive Stat3 activity up-regulates VEGF expression and tumor angiogenesis," Oncogene, vol. 21, no. 13, pp. 2000-2008, 2002.

[76] D. Wei, X. Le, L. Zheng et al., "Stat3 activation regulates the expression of vascular endothelial growth factor and human pancreatic cancer angiogenesis and metastasis," Oncogene, vol. 22, no. 3, pp. 319-329, 2003.

[77] Q. Xu, J. Briggs, S. Park et al., “Targeting Stat3 blocks both HIF1 and VEGF expression induced by multiple oncogenic growth signaling pathways," Oncogene, vol. 24, no. 36, pp. 5552-5560, 2005.

[78] M. Bartoli, D. Platt, T. Lemtalsi et al., "VEGF differentially activates STAT3 in microvascular endothelial cells," The FASEB, vol. 17, no. 11, pp. 1562-1564, 2003.

[79] Y. Yahata, Y. Shirakata, S. Tokumaru et al., "Nuclear translocation of phosphorylated STAT3 is essential for vascular endothelial growth factor-induced human dermal microvascular endothelial cell migration and tube formation," Journal of Biological Chemistry, vol. 278, no. 41, pp. 40026-40031, 2003.

[80] G. L. Semenza, "Targeting HIF-1 for cancer therapy," Nature Reviews Cancer, vol. 3, no. 10, pp. 721-732, 2003.

[81] M.-K. Oh, H.-J. Park, N.-H. Kim, S.-J. Park, I.-Y. Park, and I.-S. Kim, "Hypoxia-inducible factor- $1 \alpha$ enhances haptoglobin gene expression by improving binding of STAT3 to the promoter," Journal of Biological Chemistry, vol. 286, no. 11, pp. 8857-8865, 2011.

[82] B. Groner, P. Lucks, and C. Borghouts, "The function of Stat3 in tumor cells and their microenvironment," Seminars in Cell and Developmental Biology, vol. 19, no. 4, pp. 341-350, 2008.

[83] L. Zhang, D. Alizadeh, M. van Handel, M. Kortylewski, H. Yu, and B. Badie, "Stat3 inhibition activates tumor macrophages and abrogates glioma growth in mice," GLIA, vol. 57, no. 13, pp. 14581467, 2009.

[84] A. M. Gamero, H. A. Young, and R. H. Wiltrout, "Inactivation of Stat3 in tumor cells: releasing a brake on immune responses against cancer?" Cancer Cell, vol. 5, no. 2, pp. 111-112, 2004.

[85] H. Yu, D. Pardoll, and R. Jove, "STATs in cancer inflammation and immunity: a leading role for STAT3," Nature Reviews Cancer, vol. 9, no. 11, pp. 798-809, 2009.

[86] W. Zou, "Immunosuppressive networks in the tumour environment and their therapeutic relevance," Nature Reviews Cancer, vol. 5, no. 4, pp. 263-274, 2005.

[87] A. P. Vicari, C. Caux, and G. Trinchieri, "Tumour escape from immune surveillance through dendritic cell inactivation," Seminars in Cancer Biology, vol. 12, no. 1, pp. 33-42, 2002.
[88] H. Yu, M. Kortylewski, and D. Pardoll, "Crosstalk between cancer and immune cells: role of STAT3 in the tumour microenvironment," Nature Reviews Immunology, vol. 7, no. 1, pp. 41-51, 2007.

[89] A. C. Bharti, N. Donato, and B. B. Aggarwal, "Curcumin (diferuloylmethane) inhibits constitutive and IL-6-inducible STAT3 phosphorylation in human multiple myeloma cells," Journal of Immunology, vol. 171, no. 7, pp. 3863-3871, 2003.

[90] W. Glienke, L. Maute, J. Wicht, and L. Bergmann, “Curcumin inhibits constitutive STAT3 phosphorylation in human pancreatic cancer cell lines and downregulation of Survivin/BIRC5 gene expression," Cancer Investigation, vol. 28, no. 2, pp. 166$171,2010$.

[91] G. G. Mackenzie, N. Queisser, M. L. Wolfson, C. G. Fraga, A. M. Adamo, and P. I. Oteiza, "Curcumin induces cell-arrest and apoptosis in association with the inhibition of constitutively active NF- $\kappa$ B and STAT3 pathways in Hodgkin's lymphoma cells," International Journal of Cancer, vol. 123, no. 1, pp. 56-65, 2008.

[92] N. Chakravarti, J. N. Myers, and B. B. Aggarwal, "Targeting constitutive and interleukin-6-inducible signal transducers and activators of transcription 3 pathway in head and neck squamous cell carcinoma cells by curcumin (diferuloylmethane)," International Journal of Cancer, vol. 119, no. 6, pp. 1268-1275, 2006.

[93] S. Uddin, A. R. Hussain, P. S. Manogaran et al., "Curcumin suppresses growth and induces apoptosis in primary effusion lymphoma," Oncogene, vol. 24, no. 47, pp. 7022-7030, 2005.

[94] R. Blasius, S. Reuter, E. Henry, M. Dicato, and M. Diederich, "Curcumin regulates signal transducer and activator of transcription (STAT) expression in K562 cells," Biochemical Pharmacology, vol. 72, no. 11, pp. 1547-1554, 2006.

[95] J. H. Seo, K. J. Jeong, W. J. Oh et al., "Lysophosphatidic acid induces STAT3 phosphorylation and ovarian cancer cell motility: their inhibition by curcumin," Cancer Letters, vol. 288, no. 1, pp. 50-56, 2010.

[96] M. A. Bill, J. R. Fuchs, C. Li et al., "The small molecule curcumin analog FLLL32 induces apoptosis in melanoma cells via STAT3 inhibition and retains the cellular response to cytokines with anti-tumor activity," Molecular Cancer, vol. 9, article 165, 2010.

[97] M. Jang, L. Cai, G. O. Udeani et al., "Cancer chemopreventive activity of resveratrol, a natural product derived from grapes," Science, vol. 275, no. 5297, pp. 218-220, 1997.

[98] A. Kotha, M. Sekharam, L. Cilenti et al., "Resveratrol inhibits Src and Stat 3 signaling and induces the apoptosis of malignant cells containing activated Stat3 protein," Molecular Cancer Therapeutics, vol. 5, no. 3, pp. 621-629, 2006.

[99] A. Bhardwaj, G. Sethi, S. Vadhan-Raj et al., "Resveratrol inhibits proliferation, induces apoptosis, and overcomes chemoresistance through down-regulation of STAT3 and nuclear factor$\kappa \mathrm{B}$-regulated antiapoptotic and cell survival gene products in human multiple myeloma cells," Blood, vol. 109, no. 6, pp. 22932302, 2007.

[100] B. S. Wung, M. C. Hsu, C. C. Wu, and C. W. Hsieh, "Resveratrol suppresses IL-6-induced ICAM-1 gene expression in endothelial cells: effects on the inhibition of STAT3 phosphorylation," Life Sciences, vol. 78, no. 4, pp. 389-397, 2005.

[101] L.-J. Yu, M.-L. Wu, H. Li et al., "Inhibition of STAT3 expression and signaling in resveratrol-differentiated medulloblastoma cells," Neoplasia, vol. 10, no. 7, pp. 736-744, 2008. 
[102] Y.-P. Yang, Y.-L. Chang, P.-I. Huang et al., "Resveratrol suppresses tumorigenicity and enhances radiosensitivity in primary glioblastoma tumor initiating cells by inhibiting the STAT3 axis," Journal of Cellular Physiology, vol. 227, no. 3, pp. 976-993, 2012.

[103] H. H. Sedlacek, "Mechanisms of action of flavopiridol," Critical Reviews in Oncology/Hematology, vol. 38, no. 2, pp. 139-170, 2001.

[104] Y. K. Lee, C. R. Isham, S. H. Kaufman, and K. C. Bible, "Flavopiridol disrupts STAT3/DNA interactions, attenuates STAT3-directed transcription, and combines with the Jak kinase inhibitor AG490 to achieve cytotoxic synergy," Molecular Cancer Therapeutics, vol. 5, no. 1, pp. 138-148, 2006.

[105] F. Arguello, M. Alexander, J. A. Sterry et al., "Flavopiridol induces apoptosis of normal lymphoid cells, causes immunosuppression, and has potent antitumor activity in vivo against human leukemia and lymphoma xenografts," Blood, vol. 91, no. 7, pp. 2482-2490, 1998.

[106] Y. Dai, M. Rahmani, X.-Y. Pei, P. Dent, and S. Grant, "Bortezomib and flavopiridol interact synergistically to induce apoptosis in chronic myeloid leukemia cells resistant to imatinib mesylate through both $\mathrm{Bcr} / \mathrm{Abl}$-dependent and -independent mechanisms," Blood, vol. 104, no. 2, pp. 509-518, 2004.

[107] Y.-W. Chen, K.-H. Chen, P.-I. Huang et al., "Cucurbitacin I suppressed stem-like property and enhanced radiation-induced apoptosis in head and neck squamous carcinoma-derived $\mathrm{CD}_{4} 4^{+} \mathrm{ALDH1}^{+}$cells," Molecular Cancer Therapeutics, vol. 9, no. 11, pp. 2879-2892, 2010.

[108] M. A. Blaskovich, J. Sun, A. Cantor, J. Turkson, R. Jove, and S. M. Sebti, "Discovery of JSI-124 (cucurbitacin I), a selective Janus kinase/signal transducer and activator of transcription 3 signaling pathway inhibitor with potent antitumor activity against human and murine cancer cells in mice," Cancer Research, vol. 63, no. 6, pp. 1270-1279, 2003.

[109] G. B. Iwanski, D. H. Lee, S. En-Gal et al., "Cucurbitacin B, a novel in vivo potentiator of gemcitabine with low toxicity in the treatment of pancreatic cancer," British Journal of Pharmacology, vol. 160, no. 4, pp. 998-1007, 2010.

[110] J. Sun, M. A. Blaskovich, R. Jove, S. K. Livingston, D. Coppola, and S. M. Sebti, "Cucurbitacin Q: a selective STAT3 activation inhibitor with potent antitumor activity," Oncogene, vol. 24, no. 20, pp. 3236-3245, 2005.

[111] W.-W. Huang, J.-S. Yang, M.-W. Lin et al., "Cucurbitacin e induces G2/M phase arrest through STAT3/p53/p21 signaling and provokes apoptosis via Fas/CD95 and mitochondriadependent pathways in human bladder cancer T24 cells," Evidence-Based Complementary and Alternative Medicine, vol. 2012, Article ID 952762, 11 pages, 2012.

[112] H. Song, R. Wang, S. Wang, and J. Lin, "A low-molecularweight compound discovered through virtual database screening inhibits Stat 3 function in breast cancer cells," Proceedings of the National Academy of Sciences of the United States of America, vol. 102, no. 13, pp. 4700-4705, 2005.

[113] M. Weidler, J. Rether, T. Anke, and G. Erkel, "Inhibition of interleukin- 6 signaling and Stat 3 activation by a new class of bioactive cyclopentenone derivatives," Biochemical and Biophysical Research Communications, vol. 276, no. 2, pp. 447-453, 2000.

[114] A. Eberhard, A. L. Burlingame, C. Eberhard, G. L. Kenyon, K. H. Nealson, and N. J. Oppenheimer, "Structural identification of autoinducer of Photobacterium fischeri luciferase," Biochemistry, vol. 20, no. 9, pp. 2444-2449, 1981.
[115] L. Li, D. Hooi, S. R. Chhabra, D. Pritchard, and P. E. Shaw, "Bacterial $\mathrm{N}$-acylhomoserine lactone-induced apoptosis in breast carcinoma cells correlated with down-modulation of STAT3," Oncogene, vol. 23, no. 28, pp. 4894-4902, 2004.

[116] R. Hoessel, S. Leclerc, J. A. Endicott et al., "Indirubin, the active constituent of a Chinese antileukaemia medicine, inhibits cyclin-dependent kinases," Nature Cell Biology, vol. 1, no. 1, pp. 60-67, 1999.

[117] K. H. Merz, S. Schwahn, F. Hippe, S. Mühlbeyer, S. Jakobs, and G. Eisenbrand, "Novel indirubin derivatives, promising anti-tumor agents inhibiting cyclin-dependent kinases," International Journal of Clinical Pharmacology and Therapeutics, vol. 42, no. 11, pp. 656-658, 2004.

[118] S. Nam, R. Buettner, J. Turkson et al., "Indirubin derivatives inhibit Stat3 signaling and induce apoptosis in human cancer cells," Proceedings of the National Academy of Sciences of the United States of America, vol. 102, no. 17, pp. 5998-6003, 2005.

[119] L. Liu, S. Nam, Y. Tian et al., “6-Bromoindirubin-3'-oxime inhibits JAK/STAT3 signaling and induces apoptosis of human melanoma cells," Cancer Research, vol. 71, no. 11, pp. 3972-3979, 2011.

[120] Y. Zhen, V. Sørensen, Y. Jin, Z. Suo, and A. Więdłocha, "Indirubin- $3^{\prime}$-monoxime inhibits autophosphorylation of FGFR1 and stimulates ERK1/2 activity via p38 MAPK," Oncogene, vol. 26, no. 44, pp. 6372-6385, 2007.

[121] Z. Ni, W. Lou, E. S. Leman, and A. C. Gao, "Inhibition of constitutively activated Stat 3 signaling pathway suppresses growth of prostate cancer cells," Cancer Research, vol. 60, no. 5, pp. 12251228,2000

[122] J. De Vos, M. Jourdan, K. Tarte, C. Jasmin, and B. Klein, “JAK2 tyrosine kinase inhibitor tyrphostin AG490 downregulates the mitogen-activated protein kinase (MAPK) and signal transducer and activator of transcription (STAT) pathways and induces apoptosis in myeloma cells," British Journal of Haematology, vol. 109, no. 4, pp. 823-828, 2000.

[123] D. Kube, U. Holtick, M. Vockerodt et al., "STAT3 is constitutively activated in Hodgkin cell lines," Blood, vol. 98, no. 3, pp. 762-770, 2001.

[124] M. Nielsen, K. Kaltoft, M. Nordahl et al., "Constitutive activation of a slowly migrating isoform of Stat 3 in mycosis fungoides: tyrphostin AG490 inhibits Stat3 activation and growth of mycosis fungoides tumor cell lines," Proceedings of the National Academy of Sciences of the United States of America, vol. 94, no. 13, pp. 6764-6769, 1997.

[125] U. Holtick, M. Vockerodt, D. Pinkert et al., "STAT3 is essential for Hodgkin lymphoma cell proliferation and is a target of tyrphostin AG17 which confers sensitization for apoptosis," Leukemia, vol. 19, no. 6, pp. 936-944, 2005.

[126] S. Verstovsek, H. Kantarjian, R. A. Mesa et al., "Safety and efficacy of INCB018424, a JAK1 and JAK2 inhibitor, in myelofibrosis," The New England Journal of Medicine, vol. 363, no. 12, pp. 1117-1127, 2010.

[127] A. Quintás-Cardama, H. Kantarjian, J. Cortes, and S. Verstovsek, "Janus kinase inhibitors for the treatment of myeloproliferative neoplasias and beyond," Nature Reviews Drug Discovery, vol. 10, no. 2, pp. 127-140, 2011.

[128] S. . Verstovsek, C. Machida, J. P. Dean, and H. Myint, "Pacritinib. Inhibitor of tyrosine-protein kinase JAK2, inhibitor of FLT-3, treatment of myelofibrosis," Drugs of the Future, vol. 38, no. 6, pp. 375-386, 2013. 
[129] M. Hedvat, D. Huszar, A. Herrmann et al., "The JAK2 inhibitor AZD1480 potently blocks Stat 3 signaling and oncogenesis in solid tumors," Cancer Cell, vol. 16, no. 6, pp. 487-497, 2009.

[130] C. Houssier, M. C. Depauw-Gillet, R. Hacha, and E. Fredericq, "Alteration in the nucleosome and chromatin structures upon interaction with platinum coordination complexes," Biochimica et Biophysica Acta, vol. 739, no. 3, pp. 317-325, 1983.

[131] J. Deng, F. Grande, and N. Neamati, "Small molecule inhibitors of Stat3 signaling pathway," Current Cancer Drug Targets, vol. 7, no. 1, pp. 91-107, 2007.

[132] H. Song, V. K. Sondak, D. L. Barber, T. J. Reid, and J. Lin, "Modulation of Janus kinase 2 by cisplatin in cancer cells," International journal of oncology, vol. 24, no. 4, pp. 1017-1026, 2004.

[133] J. Turkson, S. Zhang, J. Palmer et al., "Inhibition of constitutive signal transducer and activator of transcription 3 activation by novel platinum complexes with potent antitumor activity," Molecular Cancer Therapeutics, vol. 3, no. 12, pp. 1533-1542, 2004.

[134] J. Turkson, S. Zhang, L. B. Mora, A. Burns, S. Sebti, and R. Jove, "A novel platinum compound inhibits constitutive Stat3 signaling and induces cell cycle arrest and apoptosis of malignant cells," Journal of Biological Chemistry, vol. 280, no. 38, pp. 32979-32988, 2005.

[135] S. R. Choudhari, M. A. Khan, G. Harris et al., "Deactivation of Akt and STAT3 signaling promotes apoptosis, inhibits proliferation, and enhances the sensitivity of hepatocellular carcinoma cells to an anticancer agent, Atiprimod," Molecular Cancer Therapeutics, vol. 6, no. 1, pp. 112-121, 2007.

[136] M. Amit-Vazina, S. Shishodia, D. Harris et al., "Atiprimod blocks STAT3 phosphorylation and induces apoptosis in multiple myeloma cells," British Journal of Cancer, vol. 93, no. 1, pp. 7080, 2005.

[137] M. Wang, L. Zhang, X. Han et al., "Atiprimod inhibits the growth of mantle cell lymphoma in vitro and in vivo and induces apoptosis via activating the mitochondrial pathways," Blood, vol. 109, no. 12, pp. 5455-5462, 2007.

[138] S. Faderl, A. Ferrajoli, D. Harris, Q. Van, H. M. Kantarjian, and Z. Estrov, "Atiprimod blocks phosphorylation of JAK-STAT and inhibits proliferation of acute myeloid leukemia (AML) cells," Leukemia Research, vol. 31, no. 1, pp. 91-95, 2007.

[139] J. E. Frampton and R. N. Brogden, "Pentoxifylline (oxpentifylline). A review of its therapeutic efficacy in the management of peripheral vascular and cerebrovascular disorders," Drugs \& Aging, vol. 7, no. 6, pp. 480-503, 1995.

[140] M. Z. . Kamran and R. P. Gude, "Preclinical evaluation of the antimetastatic efficacy of Pentoxifylline on A375 human melanoma cell line," Biomedicine \& Pharmacotherapy, vol. 66, no. 8, pp. 617-626, 2012.

[141] M. Z. . Kamran and R. P. Gude, "Pentoxifylline inhibits melanoma tumor growth and angiogenesis by targeting STAT3 signaling pathway," Biomedicine \& Pharmacotherapy, vol. 67, no. 5, pp. 399-405, 2013.

[142] P. L. Leong, G. A. Andrews, D. E. Johnson et al., "Targeted inhibition of Stat 3 with a decoy oligonucleotide abrogates head and neck cancer cell growth," Proceedings of the National Academy of Sciences of the United States of America, vol. 100, no. 7, pp. 4138-4143, 2003.

[143] S. Xi, W. E. Gooding, and J. R. Grandis, "In vivo antitumor efficacy of STAT3 blockade using a transcription factor decoy approach: implications for cancer therapy," Oncogene, vol. 24, no. 6, pp. 970-979, 2005.
[144] M. Sen, S. M. Thomas, S. Kim et al., "First-in-human trial of a STAT3 decoy oligonucleotide in head and neck tumors: implications for cancer therapy," Cancer Discovery, vol. 2, no. 8, pp. 694-705, 2012.

[145] X. Zhang, J. Zhang, L. Wang, H. Wei, and Z. Tian, “Therapeutic effects of STAT3 decoy oligodeoxynucleotide on human lung cancer in xenograft mice," BMC Cancer, vol. 7, article 149, 2007.

[146] J. Shen, R. Li, and G. Li, "Inhibitory effects of decoy-ODN targeting activated STAT3 on human glioma growth in vivo," In Vivo, vol. 23, no. 2, pp. 237-243, 2009. 


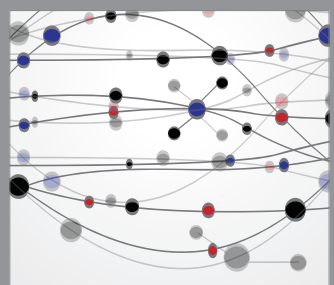

The Scientific World Journal
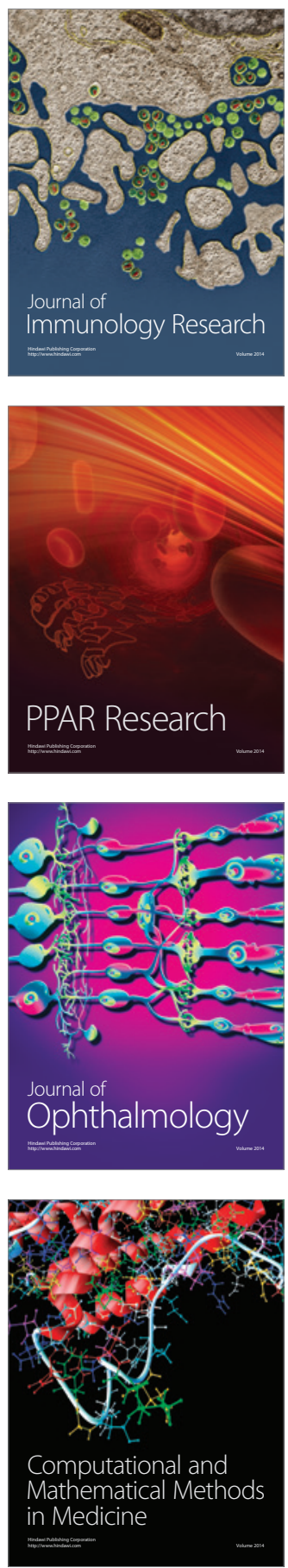

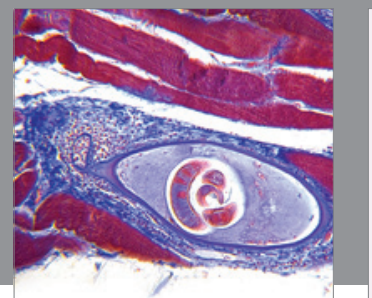

Gastroenterology

Research and Practice
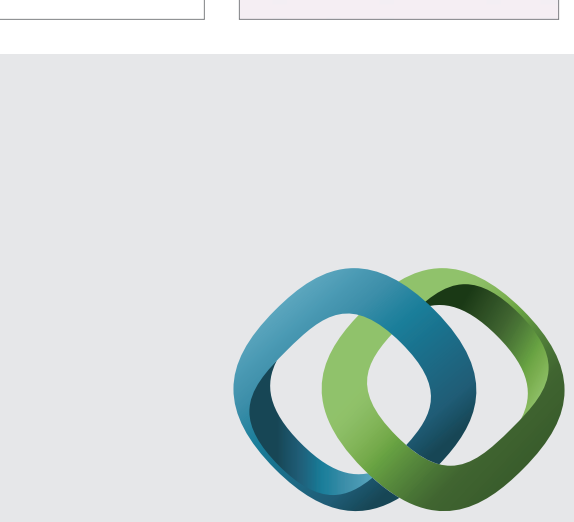

\section{Hindawi}

Submit your manuscripts at

http://www.hindawi.com
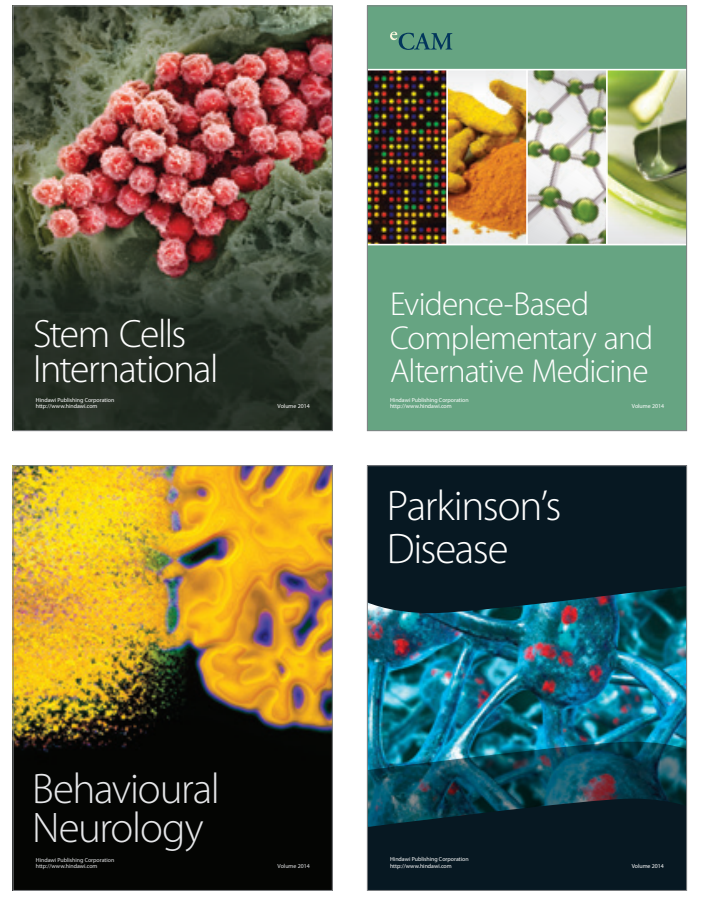
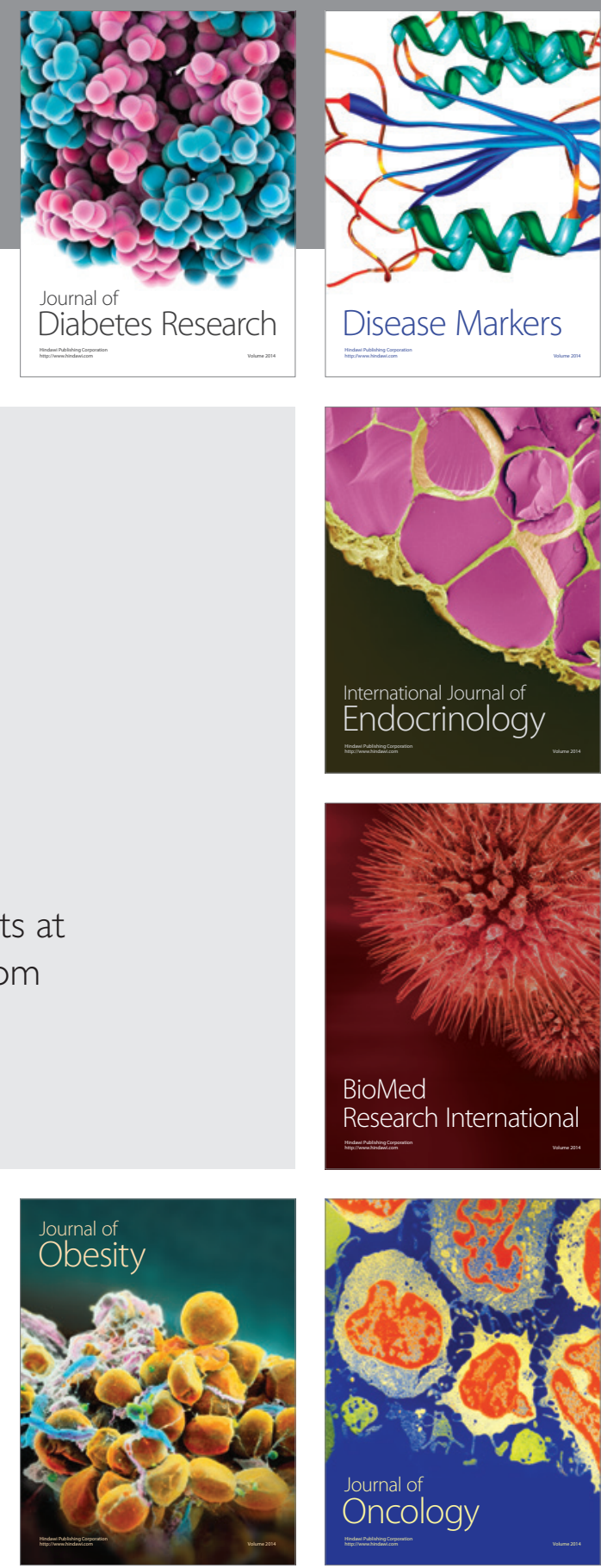

Disease Markers
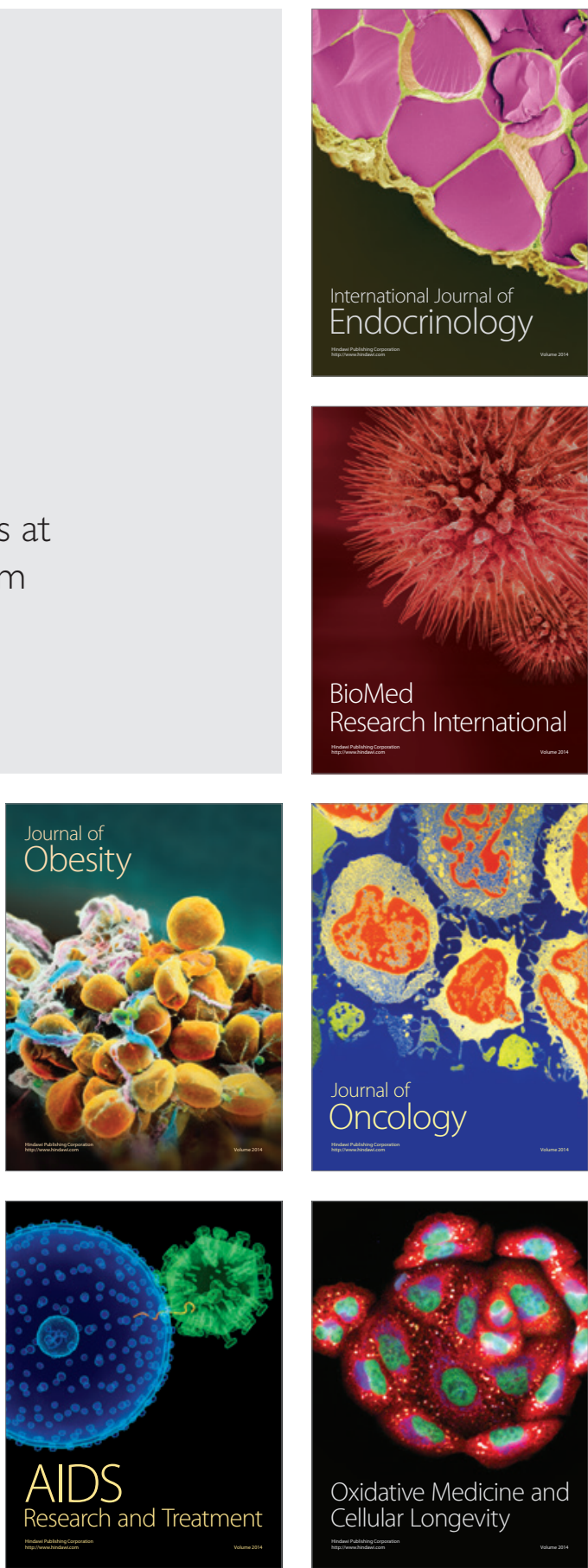